\title{
Identity work in developing collaborative leadership
}

\section{Barbara Simpson and Brigid Carroll}

Barbara Simpson is Professor of Leadership and Organisational Dynamics at Strathclyde Business School in Glasgow, UK.

Brigid Carroll is Associate Professor in the Department of Management and International Business at the University of Auckland Business School in New Zealand.

\begin{abstract}
This chapter uses leadership development as a portal to understanding how identity work is collaboratively practiced in organizations. At the same time it explores an organizationally sanctioned liminality that continuously produces identity work in the performative interweaving of traveling concepts. Advancing this link between leadership development and identity work, we engage a processual re-theorization that posits identity work as liminal practice - emergent, edgy, ephemeral, precarious, and fluid in nature - and leadership development as concerned with making visible the implicit identity work undertaken within this liminality. We illustrate our argument with insights from a leadership studio workshop, which sought to develop collaborative leadership within a recently formed public health and social care service where identity work continuously shapes, and is shaped by the development of a more inclusive and dynamic leadership practice.
\end{abstract}

\section{Keywords}

Identity work, liminality, traveling concepts, performativity, betwixt-and-between, process ontology, health and social care 


\section{Introduction}

As is abundantly demonstrated by this Handbook, identity continues to be an enormously productive construct in organization studies. The potential for identity to explore across levels of analysis, internal and external organizational boundaries, and ethnic and cultural differences has made it an indispensable tool in almost every aspect of organizational research (Alvesson, Ashcraft, \& Thomas, 2008). However, with contemporary trends towards post-industrial models of organization that involve flexible employment, temporary and fixed-term contracts, and complex dynamic networks rather than rigid bureaucratic structures, conventional thinking about stable and durable identities in organizations is being overtaken by the concept of continuously re-built, ephemeral, chameleon-like identities that can shift and morph with changing conditions (Ybema, Beech, \& Ellis, 2011). Research interest is accordingly turning towards the work of making identities (Alvesson \& Willmott, 2002; Brown, 2015), where this is widely understood as a dynamic social process characterized by precarity and emergent becoming, in which organizational actors work together to simultaneously reconstruct their selves and their worlds.

This performative perspective on identity work evokes new metaphors of inquiry that are able to engage with the uncertainty and ambiguity of continuous change (Czarniawska \& Mazza, 2003). For example, the notion of 'liminality' has already been linked to identity work in a variety of studies including the flexible nature of employment (Beech, 2011), the management of temporary projects (Paton \& Hodgson, 2016), as an apparatus for culture change (HowardGrenville, Golden-Biddle, Irwin, \& Mao, 2011) or a mechanism for training and development (Hawkins \& Edwards, 2015), and as a description of consulting practice (Czarniawska \& Mazza, 2003). In its original conception (Turner, 1987; Van Gennep, 1909 [1960]), liminality refers to the transition between stable identity states during which the usual social structures 
and their associated obligations are suspended. The liminar undergoing transition effectively stands outside conventional definition and is, therefore, socially invisible (Beech, 2011). In its application to organization and management, Söderlund and Borg (2017) demonstrate that this conception has been significantly extended beyond the sequential evolution between preliminal and post-liminal states, to make more visible the positions and roles of liminars in this process, and the liminal space within which the transition takes place. However, they also suggest there is still more that could be mined from this metaphor, especially in relation to the temporal dimensions of liminality and the dynamics of learning and development.

It is this challenge that we take up here. In particular, we want to go beyond the mere sequentiality of a process that moves from one fixed and stable identity to another, by engaging a processual ontology that attends to the emergent movements and flows of actually doing identity work. We illustrate our argument using examples drawn from a leadership studio workshop (Simpson \& Buchan, 2018) that was designed to develop collaborative public leadership, where leadership is explicitly conceived as a perpetually liminal practice that is both fluid and emergent. In this context, leadership development is accomplished in the work of actually doing leadership, and as such it is deeply entwined with, and inseparable from identity work. We begin in the next section by elaborating the mutuality of leadership development and identity work. Our argument then proceeds to develop the theoretical and methodological implications of liminality for identity work, which we then explore empirically in the context of developing collaborative leadership. 


\section{Identity work and leadership development}

Identity-based research has served to unsettle and disrupt traditional leadership scholarship, which tends to privilege the psychometric assessment of those traits, behaviours and contingencies by means of which leaders are deemed to operate. Such approaches frame leadership in terms of performance, effectiveness and activity, with leadership development responding to questions about what leaders should do and how those things should be done. Identity researchers on the other hand approach leadership critically, as a social construct that offers resources in terms of power, meaning significance and relationship. Here, leadership development asks different questions about what leadership might facilitate, enable and constrain between actors in their various moments and contexts (Mabey, 2013).

Identity approaches to leadership development have shone a light on processes that shape, direct and influence the emergence of leadership, such as the idealized and desired identities that are structured into programme purposes and designs, and which serve to regulate participant identity choices (Gagnon \& Collinson, 2014), power and resistance dynamics between participants and educators (Carroll \& Nicholson, 2014), and the facilitated processes of constructing and undoing identity (Nicholson \& Carroll, 2013). This focus on identity has shown that claims relating leadership construction to a discrete self are nebulous, that actors inhabit leadership in myriad ways that require sustained reflexivity and sensemaking to understand, and that leadership connects with other organizational and societal discourses of control, legitimation and expectation in profound and not always transparent ways. Nevertheless, identity research in leadership continues to be rather static as it focusses more on the drivers and results of identity work than the movements of the work itself. 
At first glance theories of identity work appear to embrace change, transition and flux as core features. After all identity work is generally taken to be synonymous with struggle (Sveningsson \& Alvesson, 2003) and it is frequently characterized using verbs as 'being continuously engaged in forming, repairing, maintaining, strengthening, or revising' identities (Alvesson \& Willmott, 2002: 626). Identity work has always been viewed as a process that is discursively produced and materially mediated, and as such it is steeped in flux, fragmentation and contradiction (Simpson \& Carroll, 2008). However, research on identity work has most often assumed that the end goal is continuity and consistency 'whereby people strive to shape a relatively coherent and distinctive notion of personal self-identity' (Watson, 2009: 429). This speaks to a preference for 'settled selves' where subjects retrospectively impose a sense of narrative order and cohesion on their identity accounts, often as a response to perceived researcher expectations in interviews. Critiquing this tendency towards equilibrium, identity researchers have turned their attention to drivers such as impression management and political positioning in identity-oriented interviewing (Alvesson \& Sveningsson, 2003). These concepts are equally important for leadership development programmes, especially given that participants often feel they must reaffirm their desirability and organizational value regardless of their own struggles with leadership and its demands.

A second critique that concerns us here is the privileging of the individual and personal in identity research. This has been confronted head-on by scholars such as Watson (2008) who sees a reluctance to grapple with the social, structural and contextual forces that provide significant 'extra-individual discourses' as important resources for identity work (Alvesson et al., 2008: 23). Watson (2009: 688) proposes "nested" levels' that nestle personal identity in larger spheres of organizational and societal narratives. Again this concern is equally resonant 
in a leadership development context where any act of leading inevitably includes others, necessitating greater relational and situational sophistication in both theory and practice.

In order to respond to these critiques of identity work, particularly in the context of leadership development, we argue here for a very different approach to theorization, one that more readily engages with the flows and movements of socially embedded leadership practice. In the next section, we develop 'liminality' as an alternative metaphor to inform new identity work theory, one that replaces any hankering after cohesion, order and permanence with the edginess of understanding oneself 'betwixt-and-between', always on the cusp of multiple sites and locations, and always in motion. This explicitly processual approach requires an ontological shift that steps away from the stabilized certainties of representationalism in order to plunge directly into the performative flows of practice (James, 1912 [2006]; Shotter, 2006).

\section{Understanding the liminality of identity work}

The notion of 'liminality' can be traced back to van Gennep's (1909 [1960]) studies of the ritualized rites of passage practiced by different cultures. He observed three distinct phases in these rituals: separation, transition, and incorporation. For instance, in a 'coming of age' ritual, the child is first separated from the social group that identifies her status as 'child'; then through a developmental process she transitions to a new state of adulthood; and finally she is incorporated into this new social status. Czarniawska and Mazza (2003) point out that this ritual process is equally relevant in the world of contemporary organization where, for instance, when trainees are recruited they are separated from their previous lives as students, then they are developed through specialized training schemes, and ultimately they are welcomed as fullyfledged managers. This three-phase passage chimes with Lewin's (1947) familiar model of change management - unfreeze, change, refreeze - and may be equally criticized for over- 
simplifying a complex and ongoing process by assuming it is bookended by stable positions that define fixed start and end points. In other words, both models privilege states of stability and equilibrium, relegating the dynamics of change and transition to effects that are secondary and derivative. This same critique is what motivates our quest in this chapter to explore the dynamic movements of identity work.

It was only after van Gennep's work was translated into English in 1960 that Turner (1979, 1987) began to elaborate 'liminality' in the field of anthropology. Like van Gennep, he sees it as a vehicle for transition in the context of sociocultural status change, but he is particularly interested in exploring the liminal phase, which he describes as 'being-on-a-threshold ... a state or process which is betwixt-and-between the normal, day-to-day cultural and social states' (1979: 465). It is, in effect, a learning process that combines experimentation and reflection. Liminality is thus 'full of potency and potentiality ... experiment and play' (1979: 466), but although it may release creativity, it can also generate anxiety when people come to realize they have slipped their moorings to familiar realities. For Turner, liminality must be understood as simultaneously spatial and temporal, but '[s]ince liminal time is not controlled by the clock it is a time of enchantment when anything might, even should, happen' (1979: 465, emphasis in original). In seeking an alternative to clock time, Turner (1979) invokes Csikszentmihalyi's (1975) notion of 'flow' to describe the continuity of experience that transcends the common dualistic distinctions between self and social, and between past, present and future.

There is a remarkable resemblance between Turner's understanding of liminality and the earlier writing of Mead (1932) on the subject of sociality, which he defines as the movement 'betwixt and between the old system and the new' (73) and 'the capacity of being several things at once' (75). It is sociality that allows us to engage with our own and others' multiple and shifting 
identities in the unfolding process of identity work. Indeed it is this capacity that, for Mead, is the defining quality of what it means to be social. We are social to the extent that we are able to walk in the shoes of others and take on attitudes other than our own. Sociality then, is the social process of reconstructing meanings in changeful situations, and it is sociality that brings meaning to our socially engaged experience (Carroll \& Simpson, 2012). Like Turner's take on liminality, Mead's sociality is both spatial and temporal as the 'betwixt and between' signifies not only a state of in-between-ness, but also a process of movement within and between.

Over the past decade or so, the idea of liminality has been taken up and enthusiastically elaborated in the field of organization studies (Söderlund \& Borg, 2017). For instance, Beech (2011) pursues Turner's interest in what happens in the liminal phase of transition, suggesting that identity work is a liminal activity that arises in between self and social identities. As such, it is more of a 'negotiation between' than a 'transition between'. He finds three work practices - experimentation, recognition, reflection - that emphasize the dynamics of imaginative inquiry in the co-constituting of liminal experience. This formulation nevertheless depends on more or less stable, dualistic states that bookend, and contain liminal activities. Others have focussed attention on the liminars, the occupants of liminal space, attending to the work-related experience of certain roles or positions in organizations, such as consultants (Czarniawska \& Mazza, 2003), temporary workers (Garsten, 1999), project managers (Paton \& Hodgson, 2016), and the participants in leadership development programmes (Hawkins \& Edwards, 2015). Still others have explored the liminal space, its physicality and materiality, where liminal activities can develop outside the normal constraints of organization (e.g. Johnson, Prashantham, Floyd, \& Bourque, 2010; Sturdy, Schwarz, \& Spicer, 2006). However both these streams of research, liminal position and liminal space, downplay the processual emergence of liminality in favour of the spatial entities that populate and contain its movements. 
As originally conceived by van Gennep and Turner, liminality is necessarily a temporary condition, but somewhat paradoxically, organizational scholars are increasingly describing it as a permanent in-between state. Johnsen and Sørensen (2015) argue that modern organization is characterized by a permanent state of crisis, a perpetual urgency, suggesting that change rather than stability has become the norm. Whereas organizational change has traditionally been justified in terms of establishing a new stability, today temporariness and transition have become institutionalized as an enduring state of ambiguity and uncertainty. In the words of Czarniawska and Mazza (2003: 269) 'liminality is becoming the modern condition'. Whilst these are fruitful developments of 'liminality' as a concept, in our view they are still somewhat constrained by the idea that permanent liminality is conceived as a state located between other states. Bamber, Allen-Collinson, and McCormack (2017) make a useful distinction by opposing the common conflation of liminality with a state of limbo. For them, limbo implies an irredeemable stuckness that is 'always-this-and-never-that', whereas liminality holds the potential of being 'neither-this-nor-that, or both-this-and-that' (2017: 1514). Whilst we value this clarification, the dynamic potential for liminality as ongoing practice, rather than a state, continues to be under-explored in the organizational literature.

An obvious consequence of permanent liminality is that settled identities may never emerge, so researching identity work then demands a different sort of theoretical and empirical commitment, one that takes account of the movements, flows, experimentation and playfulness implied by being betwixt-and-between. This implies a continuously emergent liminality that is better described as perpetual than permanent (Ybema, Beech, \& Ellis, 2011). Johnsen and Sørensen (2015) approach this issue by engaging with Agamben and Deleuze, whose analyses of modern society emphasize the blurring of those categorical dualisms so pervasive in the 
organizational literature. In particular, they examine the increasingly fuzzy boundary between working and living. Our project here continues this exploration of liminality as perpetual and generative identity work that blurs the distinctions between the individual and the organizational, and between stasis and change.

In building our argument, we adopt a process ontology of becoming (Chia, 1995), which privileges the movements and flows of living practice ahead of the stabilized entities that punctuate and define the limits of process. This is not to say that entities do not exist, but rather to recognize that they are abstractions derived from the ongoing flow of process. To be clear, the sequentiality that is evident in van Gennep's understanding of liminality, the progress from pre-liminal, to liminal, and then post-liminal phases, is not what we are talking about. Rather, a process ontology requires us to shift our theoretical and empirical gaze from the stuff of the situation, or its past/present/future phases, to its continuously emergent and performative movements.

By way of illustrating these ideas, we now turn our attention to an empirical inquiry into collaborative leadership development, in which leadership is understood as liminal practice emerging continuously, without beginning or end, out of the relational dynamics of the situation. Following Mead (1932), we see these dynamics as the ongoing identity work that builds sociality. Our objective then, is not to discover certain identities that are constructed in this social process, but rather to follow the emergent flow of co-constructive identity work. We read the empirical materials through the lens of liminality, seeking to illuminate the liminal experience of perpetual in-between-ness and to trace the emergent dynamics of identity work in stories of developing collaborative leadership. 


\section{Introducing the Leadership Studio}

The leadership studio was conceived as a series of three half-day workshops conducted with a group of around 30 participants from a Scottish Health and Social Care Partnership (HSCP), one of 31 new HSCPs established in 2016 by Scottish statute with the objective of integrating the provision of healthcare and social care services across the nation. In establishing these new HSCPs, the government sought to promote new ways of working, and in particular a new mode of collaborative leadership capable of transcending the very different leadership mindsets of the predecessor Health Boards and Local Councils. The purpose of the leadership studio, which was facilitated by the first author, was to help participants from all levels of the Partnership, from directors to service users, to develop a more inclusive and more collaborative leadership practice that explicitly acknowledges and welcomes leadership at every desk and in every position across their organization.

The leadership studio was designed to draw lessons from the experience of collaborative leadership at a community justice centre (CJC) that was originally created in 2014 by the local Council, and was subsequently restructured into the new HSCP. CJC provides a range of psychological, social, and practical services to 'women with convictions' - women who have served prison sentences for serious criminal offences. From its inception, it was a multidisciplinary one-stop-shop that brings together in the same location expertise in mental and physical health, addictions, social work, housing, and prisons. CJC has always maintained a commitment to co-production that sees the professional staff working together across disciplines, and with the women who use this service, to tackle the wicked problems generated by multiple and complex care needs. Ongoing collaborative leadership has seen the purpose and vision for CJC evolve into a service that moves flexibly with the diverse and changing needs of the women, accommodating their individual capacities and motivations while also 
building a strong sense of community. As such, it is an exemplar of continuous change, and a likely site of perpetual liminality.

A variety of activities was undertaken during, and between, the three studio sessions. These included a fishbowl conversation amongst four members of CJC, two of whom were seconded from agencies external to the HSCP, one was a medical professional employed by the Health Service, and the fourth was a former user of CJC's services who now volunteers at the centre. During this conversation, the members shared their experiences of the collaborative environment within which CJC does its work while all the other studio participants actively listened to this exchange. Studio participants then broke into groups, each of which included a representative from CJC. These groups used 4D mapping techniques to construct models representing perceived obstacles to implementing CJC's collaborative style of leadership across the HSCP, and this in turn lead to discussions about how these obstacles might be overcome. A rapporteur from each group then presented their group's insights to all the studio participants, using the collaboratively constructed models to support and illustrate their presentations. The data that we use in this chapter are drawn primarily from these presentations, which were audio-recorded and transcribed. We also use some of the written 'homework' that participants undertook between studio sessions. Our analysis identifies three movements that emerged continuously as participants struggled to develop new expressions of leadership for a world in perpetual motion. 


\section{CJC as a site of perpetual liminality}

We have argued that leadership development and identity work are intimately intertwining processes that emerge in the perpetual liminality of living experience. In analysing the leadership studio data then, we have looked for movements associated with liminality, such as transition, edginess, fluidity, and being in-between. However, by virtue of their dynamic nature, these movements are difficult to apprehend in the orthodox sense of stable representational constructs. Rather than resorting to conventional and over-privileged methods of identity research such as interviewing to capture individuals' retrospective reflections (Carroll, 2016), we propose the use of traveling concepts (Simpson, Tracey, \& Weston, 2018) that can shift and morph as movements evolve. Traveling concepts reflect the recent 'mobility turn' in social research (Urry, 2007) that seeks new ways of engaging with the continuously emergent and performative qualities of social and relational action. Instead of defining fixed constructs that pre-condition the researcher's expectations, traveling concepts go with the researcher's actions in a world that is itself on the move. It is in this spirit that we now explore three traveling concepts that emerged in the work of the leadership studio: risk-taking and rulebreaking; innovating and incubating; and learning and resilience.

\section{Risk-taking and rule-breaking}

Given the traditional public service origins of the HSCP, it is perhaps not surprising that the handling of risks and rules came up repeatedly throughout the leadership studio as topics of concern. An instructive example comes from a story told by Susan ${ }^{1}$, one of the CJC participants in the fishbowl conversation, recounted here by the first author (a verbatim record of this conversation is not available):

\footnotetext{
${ }^{1}$ Pseudonyms are used in presenting the leadership studio data
} 
Susan is on secondment to CJC for a period of 2 years from an external institution that is renowned for its adherence to rules and regulations. Within her first few days in this new job, a social worker asked her for information about a specific user of CJC's services. Coming from an organization that prioritizes security and confidentiality above all else, Susan was horrified to even be asked such a question. She simply didn't know how to respond, so she just made her excuses and left the conversation as quickly as she could. Susan then sought advice from her former manager who suggested that working at CJC requires a change in mindset. She subsequently made a full adjustment to the collaborative context of CJC to the extent that she is now wondering how she will cope when her secondment ends and she returns to her normal job.

A classic reading of this story might emphasize Susan's transition from her former rule-based and security-conscious identity, through the profoundly unsettling 'horror' of liminality, to a safe landing in a more relationally responsive and collaborative identity. This type of analysis emphasizes the presumed strength and solidity of terminal identity states, but the in-betweenness and relationality of how identity work actually unfolds remains largely invisible. However, it was the actual experience of liminality, with all of its discomforts and anxieties, which pre-occupied participants in the leadership studio, particularly as they reflected on the challenges of risk-taking and rule-breaking. This was illustrated, for example, immediately following the fishbowl conversation, when studio participants listed some keywords to reflect what they had just heard: 
breaking down barriers; take risks and breach rules; taking risks to do things differently; vulnerability; moving away from the comfort zone; passion for change; and asking why?

all of which speak to the 'how' of liminality, drawing attention to the uncomfortable dynamic processes of 'breaking', 'taking', 'moving' and 'asking', in the ongoing identity work at CJC.

During the groupwork that then followed, studio participants continued to elaborate this theme. Group 1's rapporteur (R1) recounted their discussion about what it is like to be a worker at CJC:

"you're a worker and it's a bit about taking risks and it's also about having the safety net to make mistakes and how you actually deal with fear ... how do you deal with that?"

Fear emerged as a major issue for all participants, either as a source of unwelcome disruption (R1):

"on one hand you had a potential disaster, so that was to represent potentially an explosion but ... even although that partly influenced the fear ... [it] was actually more about you had the authority and support to make mistakes"

or as Group 2's rapporteur (R2) reported, as something that just needs to be dealt with: 
"once you realize the worst that could happen, so the worst is that you don't get a job, the worst thing is you lose the job you've got, And actually that's ... you'll deal with that if you've got a sense of where breaking the rules can take you"

Commenting on Susan's story from the fishbowl conversation, R2 related Group 2's view that rule-breaking can be liberating:

“once you start breaking some rules or questioning, um, like the [external service] talking about actually the freedom that comes with breaking rules and then going home at night and thinking 'I've just shared information with somebody that asked me something because everyone else was doing that at $[\mathrm{CJC}]$, and then realizing that it was alright, it was $O K$."

but for this to be the case, the right conditions need to be fostered:

[at CJC] "there was permission given for risks to be taken"

As R1 observed above, it's about having a 'safety net' that protects workers if they make 'mistakes', while R2 sees risk-aversion as a wider societal problem, rueing the fact that "we bring up our kids to not question rules and to actually expect rules ... this is about how you get hung for making mistakes".

In many ways, identities may be understood as sets of rules, or templates, that tell us how to act in certain situations, but in a context such as CJC, which is always changing and always 
confronting uncertainty, fixed identities do not serve individuals or organizations well. What is needed is a willingness to face the fear that comes with breaking rules and taking risks. It is this willingness that can liberate us from the 'horror' of not knowing what to do, and facilitate action in the face of this uncertainty.

\section{Innovating and incubating}

The perpetually changing context of CJC's work requires a fleetness of foot, a willingness to explore alternatives, and an openness to trying out new ways of service provision, all of which supposes an orientation towards continuous innovation. Rather than focussing on the big 'innovative' outcomes though, our interest here is in the myriad small moves that combine to produce novel responses in unexpected and uncertain situations. R2 reported that her group had discussed at some length the types of conditions that were created at CJC in order to foster innovation:

"We had to protect innovation because we knew if we had exposed it too early ... we might have just picked at organization and we wouldn't have got to where we are today. So thinking about that we thought in terms of the challenge, you've got the old ways ... of institutionalized thinking we've set up."

Here the group recognizes the importance of breaking away from pre-liminal 'institutionalized thinking' in order to step into the creative betwixt-and-between of liminality. However, for this breaking away to succeed, the budding new CJC had to be protected from external interference and criticism. 
“[CJC] was incubated. There were deliberate decisions taken to not allow folk to come; not to set targets"

The 4D model that Group 2 constructed to depict the challenges its members perceived in the development of collaborative leadership included a sturdy wall that created a separation between CJC and the rest of the HSCP.

"you need a wall. We were saying you needed that wall to protect, as a kind of protection to allow it to incubate and allow it to develop but also give permission to be taking risks and breaking rules. But recognizing we had to build a wall so that the folk here [pointing outside CJC on the model] couldn't see the rules being broken"

Further emphasizing the importance of this protection, David, a member of Group 2, commented:

"you've got almost like a sandbox environment that we were all very proud of, so no-one ruin it. That was the sense I got-don't anyone ruin it",

The wall served not only as a way of defending CJC's staff and their new approach to service provision, but also as protection for the users of these services. As Jason, a member of Group 1, noted: 
"Some of the protection that was put in there, it's kind of funny ... not realizing just how much in the first two years was kept down. It's as much protection for the women [service users].”

In practice however, this wall cannot be impermeable. It must be possible, although not necessarily easy, to cross from one side to the other (R2):

“We called this [pointing to an opening in the model's wall] an 'Ah but gateway', a door. So see the folk that say to you 'Ah but ye cannae do it like that'. So we're giving them a door to go through because they can go back. They can go back to the institutionalized way of thinking, because they're not gonna make it through there if it's all about the 'ah but'."

Speaking from his personal experience, Jason observed:

“the 'Ah but gateway' was such a huge, huge ... I'd love a pound for every time we've done that-aye but we've done that, aye but we've been there, aye but we've worked with these women, aye but ... The interesting thing is that some of the folk who were the loudest 'aye buts' became the strongest advocates for the service"

Incubation can never become a permanent state though. At some stage CJC has to emerge from behind this protective wall in order to continue to expand its influence and its work. Indeed, at the time of the leadership studio, this figurative wall was in the process of being dismantled, but care was also being taken to embed lessons and insights that would allow CJC to continue in its liminal ways. R2 commented that the very fact incubation was seen as 
necessary could be taken as an indictment of 'the old ways of institutionalized thinking'. However, as David commented it is because now "the genie is out of the bottle [that] to some extent is why we're here" and able to learn from this collaborative leadership studio experience.

\section{Learning and resilience}

Living with liminality evokes continuous learning as a necessary response to relentless uncertainty. Nothing, and no-one, is fixed, or at least not for very long, so new solutions and new ways of working together are always being drawn out through co-productive action. This collaborative learning dynamic was articulated particularly strongly by Group 1 (R1):

"one of the things about [CJC] that has been different is just how much we embedded the feedback from the women [service users]. It's partly the lessons that we learned, so the co-production part of it was really around ... this was a new approach to working with women in [local authority area] that we had to ensure"

CJC paid careful attention to the feedback received from the service users. There was a genuine commitment to experimentation - if something didn't work, it was taken as a learning opportunity (R1):

“you put a programme in ... women were like 'it's rubbish', and we stopped it. But we were able to evidence it and for staff it was actually about giving an assurance that it was a learning process rather than necessarily a defined position that the service was trying to deliver on" 
The service team developed resilience in this learning process by sharing knowledge and making sure that the necessary skills were never located in one person only (R1):

\begin{abstract}
"it was about learning skills and knowledge and a bit about sharing ... you do have a role and a remit within a team but the difference was that we flipped it within [CJC] where it was much more about the generic shared experience gave you a level of confidence and an assurance that you didn't need to be an expert in certain subjects but you were able to go to a particular person in the team who had that level of knowledge that was their particular contribution. So for us knowledge and skills was crucial but likewise the peer support and the collective ability to fix things and learn and get support from your peers."
\end{abstract}

It was this distributed skill that was initially so shocking for Susan (in her story above), but eventually it became a source of great encouragement and reassurance for her. This capacity for liminal learning was colourfully described by studio participants in terms of sociality and the metaphor of 'walking in another's shoes'. As part of a homework exercise, several participants commented on the usefulness of this metaphor:

"I have reflected on dialogue and standing in others' shoes. Not been easy mostly due to my own feet being deeply rooted in my own way of looking at things",

"Particularly poignant for me was the "walk in their shoes" exercise. Whilst I have been mindful for many years about including SUs [service users] in decisions about 
their care, I reflected that I give staff less autonomy in creating and enabling change within the team."

Another source of resilience for the team was what R1 described as the 'lessons log', which is a continuing record of all developments and changes at CJC:

"the lessons log would talk about why things were introduced, why things were developed, and there would be a conversation and an understanding collectively as well as individually. Some of the lessons were relevant to maybe one element of the team, Scottish Prison Service secondment for example, or service user engagement. So there would be different elements"

Although the purpose of this lessons log has changed over time from a tool for governance and planning to more of an internal management tool, it remains central to CJC's ongoing learning. It is this capacity for learning and moving, rather than adherence to targets and plans, that characterizes the experience of perpetual liminality. As R1 observed:

"for us the lessons log has been a crucial part of [CJC] rather than necessarily the bit about staff feeling constrained about their role, or by the specification, or the target setting”

“we didn't concentrate on targets at all. Targets are quite abstract ... although they were there, they weren't the frontline of it." 


\section{Reading the movements of identity work}

These three traveling concepts, risk-taking and rule-breaking, innovating and incubating, and learning and resilience, trace different types of movement in the ongoing relational processes of developing collaborative leadership. For heuristic purposes, we have presented them under three separate headings, but they can be more productively understood as continuously intertwining and co-constituting dynamics. We argue that it is out of the performative interplay between these threads of process that identity work is itself constituted as a process. We do not intend to suggest though, that entities - people, spaces, artefacts - are unnecessary or unhelpful in delineating the perpetual liminality of identity work. From a processual perspective, they can be seen as punctuating the flow, thrusting themselves into it and then subsiding once their purpose has been served. As such, entities make movement sensible by mediating liminality, re-shaping it whilst also being re-shaped by it.

The 'lessons log' is an example from the CJC experience that has both processual and entitative aspects. As we have described it above, the 'lessons log' is a continuously evolving process of living experience that reflects the learning conversations by means of which CJC develops its collaborative practice. The processual dynamics of the 'lessons log' are evident in the way its purpose has changed over time as CJC has itself transformed. At the same time, the 'lessons log' may be seen as a key artefact of identity work, a repository of information about roles, responsibilities, successes and failures, which CJC can draw on as required. What we see here is that the dual character of the 'lessons log' permits a more nuanced understanding of how identity work unfolds, in what R1 described above as a 'flipped' organization where sharing knowledge, and knowing who to ask, is more highly valued than individual skills and expertise. 
Another key aspect of the CJC experience is the space that the service occupies. On her first visit to CJC, the first author was struck by the furnishing and layout of the centre's main room. It is a large open plan room that incorporates a lounge space with low tables, sofas and comfy cushions, a dining table, and a basic kitchen area. All of this contributes to an informal, inviting, and collective environment, a relational and collaborative space that encourages conversation and sharing. As such, it is a dramatic contrast to the more formal design of an office space in which lines of desks create barriers between staff and service users. As R1 commented:

\footnotetext{
"We shaped and reshaped the environment that the women came in to. So the whole thing given much more of a lounge/dining/kitchen feel to it, more of a, homely's too strong a word, but less office kind of function. They were areas as well that we suddenly realized women actually benefitted from a much more informal space rather than something that was still relying on health and safety and barriers and the whole thing around about alarms and stuff."
}

One of the benefits of this space is that it is very flexible, so it too is capable of shifting to accommodate the various different needs that the centre has, from a simple community space to a more ordered place for meetings with external stakeholders. Thus, although we understand this space primarily through the entities that occupy it, we can also see it as fluid and flowing as needs require. There are many other examples of the interaction between processes and entities that could be drawn from CJC, but faced with a word count limit, we hope that these two will suffice to demonstrate the complementarity between processual and entitative approaches to research. 


\section{Discussion}

Many readers may be querying whether our empirical materials point to identity at all. Indeed we hope this is the case, as our intent in this chapter is to shake 'the tree' of identity scholarship in an attempt to enter into the same risky and generative liminality that the leadership studio participants speak of, to navigate the 'ah but gateway' of fear and doubt, and to learn to thrive amidst the continuous innovation of a nomadic existence (Johnsen \& Sørensen, 2015). Shaking the tree in this way, we aim to demonstrate the perpetual liminality of identity work (Ybema et al., 2011) in which there are no permanent, coherent identities. Rather identities are ephemeral and precarious as they are formed and re-formed within the dynamic flow of identity work. Deepening our understanding of identity thus requires us to develop a more dynamic mode of engagement. Before advancing this argument though, there are both theoretical and methodological challenges to tackle.

The theoretical 'branches' of this tree make "a clear analytical distinction between internal personal 'self-identities' and external discursive 'social-identities"” (Watson, 2008: 121). These 'branches' are also often considered in the absence of any meaningful contextual phenomena. As Brown (2015: 31) suggests "we are almost wholly ignorant regarding whether, for example, consonant identity work topics or strategies are drawn on and shared generally by members" and how organizations might "enable (facilitate), direct (usurp and control), partner (share-in) and impede (actively hinder) their participants' identity work". These two classic dualisms - self vs social, and substance vs context - arguably cut across the very dynamics of interest in identity work. Our response is to propose an ontologically processual approach that focusses on the 'branches' in motion, and the mutuality of their movements with those of the tree that is becoming. We have deliberately foregrounded a processual approach in this chapter because this perspective still remains significantly under- 
represented in identity scholarship (Ibarra, 1999). Whilst not denying the entities that punctuate and shape identity work, this approach gives ontological priority to the emergent movements and flows of identity in the making. It is an approach that has potential to transcend the theory vs practice dualism, which is such a pervasive problem in organizational research, by offering an alternative account that resonates directly with participants, and also more broadly with organizational practitioners, for whom this is their daily lived experience.

Methodologically, we have drawn on the 'mobility turn' to propose the notion of traveling concepts, which sensitize researchers to the empirical movements of which they themselves are also emergent aspects. By contrast, conventional empirical research focusses on the stabilities, whether defined in theory or identified in the data, which constitute the constructs that illuminate the research situation. In identity-related research, this type of empirical work feels somewhat like tunnelling through data to locate the identity components, removing them from the rest of the data pool, stripping selected material down into identity pockets, categorizing and clustering them, and then deconstructing their discursive and linguistic components. Traveling concepts allow us instead to hold liminality at the forefront of the researcher's experience, leading to a process more like snorkelling: moving slowly across the surface of the data, allowing currents to take us where they will, trying to see places to dive deeper to explore, and then re-surfacing to scan and breathe before diving again. Our attention was thus drawn more towards movements as expressed through small changes of imagery, vocabulary and tone, rather than the stuff - people, spaces, artefacts - of the emerging identity situation.

What we are proposing here is a radical reformulation of identity work that privileges 'work' with all its implications of flow, movement and change. 'Identity' then, is derived from, and 
secondary to the flow of this work. More conventional approaches take an ontologically entitative position that privileges identity ahead of process. Either way, scholars are seeking a comprehensive understanding of identity work - the difference between these two partial yet complementary accounts is simply a matter of emphasis. However, shifting the focus from entities to process has profound implications for identity scholarship, requiring a re-thinking of how we understand key concepts and how we, as researchers, participate in empirical situations. In this chapter we have contributed a processual theory that associates identity work with the liminality of collaborative leadership development, and we have also drawn out three traveling concepts to guide our practical engagement with participants in a leadership studio. From this modest beginning, we hope that other scholars of identity work may be inspired to take up the challenges of applying a process lens to the actual goings-on in organizational life. If indeed complexity and dynamism are the hallmarks of the 'modern condition' of organizing (Czarniawska \& Mazza, 2003), a process approach with its becoming ontology seems to offer a novel, and potentially productive way forward.

\section{References}

Alvesson, M., Ashcraft, K. L., \& Thomas, R. (2008). Identity Matters: Reflections on the Construction of Identity Scholarship in Organization Studies. Organization, 15(1), 528.

Alvesson, M., \& Sveningsson, S. (2003). The good visions, the bad micro-management and the ugly ambiguity: Contradictions of (non-) leadership in a knowledge-intensive company. Organization Studies, 24(6), 961-988.

Alvesson, M., \& Willmott, H. (2002). Identity regulation as organizational control: Producing the appropriate individual. Journal of Management Studies, 39 (5), 619-644. 
Bamber, M., Allen-Collinson, J., \& McCormack, J. (2017). Occupational limbo, transitional liminality and permanent liminality: New conceptual distinctions. Human Relations, $70(12), 1514-1537$.

Beech, N. (2011). Liminality and the practices of identity reconstruction. Human Relations, 64(2), 285-302.

Brown, A. D. (2015). Identities and identity work in organizations. International Journal of Management Reviews, 17(1), 20-40.

Carroll, B. (2016). Leadership as identity: A practice-based exploration. In J. A. Raelin (Ed.), Leadership-as-Practice: Theory and Application (pp. 91-109). New York: Routledge.

Carroll, B., \& Nicholson, H. (2014). Resistance and struggle in leadership development. Human Relations, 67(11), 1413-1436.

Carroll, B., \& Simpson, B. (2012). Capturing sociality in the movement between frames: An illustration from leadership development. Human Relations, 65(10), 1283-1309.

Chia, R. (1995). From Modern to Postmodern Organizational Analysis. Organization Studies, 16(4), 579-604.

Csikszentmihalyi, M. (1975). Beyond boredom and anxiety. San Francisco: Jossey-Bass.

Czarniawska, B., \& Mazza, C. (2003). Consulting as a Liminal Space. Human Relations, 56(3), 267-290.

Gagnon, S., \& Collinson, D. (2014). Rethinking Global Leadership Development Programmes: The interrelated significance of power, context and identity. Organization Studies, 35(5), 645-670.

Garsten, C. (1999). Betwixt and between: Temporary employees as liminal subjects in flexible organizations. Organization Studies, 20(4), 601-617.

Hawkins, B., \& Edwards, G. (2015). Managing the monsters of doubt: Liminality, threshold concepts and leadership learning. Management Learning, 46(1), 24-43. 
Howard-Grenville, J., Golden-Biddle, K., Irwin, J., \& Mao, J. (2011). Liminality as Cultural Process for Cultural Change. Organization Science, 22(2), 522-539.

Ibarra, H. (1999). Provisional selves: experimenting with image and identity in professional adaptation. Administrative Science Quarterly, 44(4), 764-791.

James, W. (1912 [2006]). Essays in Radical Empiricism. London: Longmans, Green and Company.

Johnsen, C. G., \& Sørensen, B. M. (2015). 'It's capitalism on coke!': From temporary to permanent liminality in organization studies. Culture and Organization, 21(4), 321337.

Johnson, G., Prashantham, S., Floyd, S. W., \& Bourque, N. (2010). The Ritualization of Strategy Workshops. Organization Studies, 31(12), 1589-1618.

Lewin, K. (1947). Frontiers in group dynamics: Concept, method and reality in social science equilibrium and social change. Human Relations, 1(1), 5-41.

Mabey, C. (2013). Leadership development in organizations: Multiple discourses and diverse practice. International Journal of Management Reviews, 15(4), 359-380.

Mead, G. H. (1932). The philosophy of the present. Illinois: La Salle.

Nicholson, H., \& Carroll, B. (2013). Identity undoing and power relations in leadership development. Human Relations, 66(9), 1225-1248.

Paton, S., \& Hodgson, D. (2016). Project managers on the edge: liminality and identity in the management of technical work. New Technology, Work and Employment, 31(1), 2640.

Shotter, J. (2006). Understanding process from within: An argument for 'withness'-thinking. Organization Studies, 27(4), 585-604.

Simpson, B., \& Buchan, L. (2018). The Leadership Studio: Learning together about public leadership. Retrieved from Glasgow: 


\section{al_Version_Small.pdf}

Simpson, B., \& Carroll, B. (2008). Re-viewing 'role' in processes of identity construction. Organization, 15(1), 29-50.

Simpson, B., Tracey, R., \& Weston, A. (2018). Traveling concepts: Performative movements in learning/playing. Management Learning, 49(3), 295-310.

Söderlund, J., \& Borg, E. (2017). Liminality in Management and Organization Studies: Process, Position and Place. International Journal of Management Reviews, 0(0).

Sturdy, A., Schwarz, M., \& Spicer, A. (2006). Guess who's coming to dinner? Structures and uses of liminality in strategic management consultancy. Human Relations, 59(7), 929960.

Sveningsson, S., \& Alvesson, M. (2003). Managing managerial identities: Organizational fragmentation, discourse and identity struggle. Human Relations, 56(10), 1163-1193.

Turner, V. (1979). Frame, flow and reflection: Ritual and drama as public liminality. Japanese Journal of Religious Studies, 6(4), 465-499.

Turner, V. (1987). Anthropology of performance. New York, NY: PAJ Publications.

Urry, J. (2007). Mobilities. Cambridge, UK: Polity Press.

Van Gennep, A. (1909 [1960]). The Rites of Passage (M. Vizedom \& G. L. Caffee, Trans.). Chicago, IL: University of Chicago Press.

Watson, T. J. (2008). Managing identity: Identity work, personal predicaments and structural circumstances. Organization, 15(1), 121-143.

Watson, T. J. (2009). Narrative, life story and the management of identity: A case study in autobiographical identity work. Human Relations, 62(3), 425-452.

Ybema, S., Beech, N., \& Ellis, N. (2011). Transitional and perpetual liminality: An identity practice perspective. Anthropology Southern Africa, 34(1-2), 21-29. 
